\title{
Is a Team Different From the Sum of Its Parts? \\ Evidence from Mutual Fund Managers
}

\begin{abstract}
This paper provides the first empirical test of the diversification of opinion theory and the group shift theory using real business data. Our data set covers management teams and single managers of US equity mutual funds. All our results clearly reject the group shift theory and support the diversification of opinion theory: extreme opinions of single team managers average out and, consequently, teams take less extreme decisions than individuals do. We find that teams follow less extreme risk strategies and less extreme investment styles than single managers do. Consequently, teams are much less likely to achieve extreme performance outcomes.
\end{abstract}

Keywords: $\quad$ Mutual Funds, Team Management, Investment Behaviour

JEL-Classification: G23, M54 


\section{Introduction}

Many decisions in business are made by teams. This raises the question how team decisions differ from decisions of individuals. The answer to this question has important implications for the optimal organization of companies and business units. The literature offers two competing hypotheses. Group shift theory (see, e.g., Myers/Lamm 1978, Kerr 1992) suggests that the team opinion gravitates towards the opinion of the most extreme team member. Consequently, teams take more extreme decisions than individuals. ${ }^{1}$ In contrast, diversification of opinion theory (see, e.g., Sah/Stiglitz, 1986, 1988, Sharpe, 1981) suggests that the team opinion is the average opinion of the team members. Extreme opinions of members in a team are averaged out and teams eventually make less extreme decisions than individuals do.

In this paper we test these two competing hypotheses by examining investment decisions of mutual fund managers. The mutual fund industry offers an ideal empirical test setting for several reasons. First, the decisions of fund managers are directly reflected in the returns of the fund and therefore can be easily observed. Second, fund managers have strong incentives to make optimal decisions since their salaries are directly linked to the performance outcomes of their decisions. Third, the mutual fund industry allows us to run tests based on a large numbers of fund managers from different firms. Thus, our results will not be driven by the priming effects of the organizational culture of a specific firm.

Our paper is the first to test the above theories in a large sample of real world data from a professional business setting. Thus far, the literature on this issue consists mainly of experimental studies (see e.g. Stoner, 1961, Moskovici/Zavalloni, 1969, Davis/Hinsz, 1982, Mulvey/Klein, 1998, and Cooper/Kagel, 2004). They find that teams take more extreme decisions than individuals, i.e. experimental studies support the group shift theory. However, it is not clear whether these experiment based results hold for real world decisions, which are typically much more complex than the decision made in experiments. Financial incentives are much stronger in real world settings and the downside risk of making wrong decision is much higher. Adams/Ferreira (2007) are the first who compare the extremity of decisions of teams and individuals in an empirical study. They analyze the behaviour of betting pools and individual betters in iceberg break-up betting and find that teams take less extreme decisions

$1 \quad$ A closely related concept is the idea of group polarization of Myers/Lamm (1976) which also predicts that teams make more extreme decisions than individuals. 
than individuals do. Although it is not clear at all whether findings on iceberg break-up betting hold in a professional business setting, their results provide a first hint that teams behave differently in real world situations than in experiments.

Our paper provides strong evidence for the diversification of opinion theory and rejects the group shift theory. We find that teams take less extreme decisions than single managers do. This holds true for risk taking decisions (total risk, systematic risk, unsystematic risk) as well as for decisions on investment style (value vs. growth, small cap vs. large cap, and momentum vs. contrarian style). ${ }^{2}$ Given these findings, it comes as no surprise that teams achieve less extreme performance outcomes than single managers. Using an instrumental variable approach, we show that our results also hold after taking into account the potential endogeneity of the management structure.

Our study contributes to three main strands of the literature. First, it contributes to mutual fund literature. Despite the growing importance of team management in the mutual fund industry, only little empirical research so far has been devoted to this issue. While there are several studies that examine performance differences between single- and team managed funds (see e.g. Prather/Middleton, 2002, 2006, Chen et al., 2004, Bär/Kempf/Ruenzi, 2005, Massa/Reuter/Zitzewitz, 2007), there are almost no studies on the behavioural differences between team fund managers and single managers. Notable exceptions are Qiu (2003) and Kempf/Ruenzi (2007) who study how teams and single managers behave differently in tournament situations. Second, our paper contributes to the management and organization literature by highlighting important behavioural differences between team and single managers. This literature so far has mainly focused on performance differences (e.g. Cooper/Kagel, 2004, Cohen/Bailey, 1997). Finally, our study also contributes to the social psychology literature on team behaviour by showing that group shift phenomenon (that has been shown in experimental studies) can not explain the behaviour of teams in a real world business setting..

We proceed as follows. In Section 2 we develop the hypotheses that emerge from the group shift theory and the diversification of opinion theory. In Section 3 we describe our data set and provide descriptive statistics. In Section 4 we report the main results of our study. In Section 5 we take into account the possible endogeneity of management structure and show that all our results remain unchanged. Section 6 concludes. 


\section{Hypotheses}

In this section we derive hypotheses that emerge from the diversification of opinion theory and the group shift theory. The predictions relate to risk-taking decisions, investment styles and performance outcomes.

\section{Diversification of Opinion Theory}

According to the diversification of opinion theory, the team opinion is simply the arithmetic mean of the opinions of the team members. This averaging has a moderating effect on the portfolio decisions and performance outcomes of teams.

Individual fund managers differ with respect to the risk they want to take due to differences in their risk aversion and their expectations regarding the market risk premium. ${ }^{3}$ Diversification of opinion theory suggests that the averaging effect leads to less extreme expectations and risk aversions within teams. Therefore, we expect teams to have a lower probability of holding portfolios with extreme high or extreme low risk:

H1: Teams choose less extreme risk positions than single managers do.

A similar reasoning holds with respect to the investment style (growth vs. value, small-cap vs. large-cap, and momentum vs. contrarian investing). Since different fund managers naturally have different preferences regarding their preferred investment styles, we expect that the averaging effect leads to less extreme investment styles of teams:

H2: Teams follow less extreme investment styles than single managers do.

If teams follow less extreme risk taking strategies and less extreme investment styles, we expect teams to achieve less extreme performance outcomes since the strategies work well in some cases, but poorly in other cases. Consequently, extreme strategies lead sometimes to

Chevalier/Ellison (1999a) provide evidence that younger managers are more risk averse than older managers due to higher termination risk. According to Niessen/Ruenzi (2006), female managers follow less risky strategies than male managers do. Bollen/Busse (2001) show that many fund managers engage in market timing, i.e. they invest more or less in risky assets dependent upon their expectation of the future market risk premium. 
extremely good performance and sometimes to extremely poor performance. Thus, the chance of achieving an extreme (good or bad) performance outcome should be higher for single managers than for teams:

H3: Teams achieve less extreme performance outcomes than single managers do.

In sum, diversification of opinion theory implies that teams choose less extreme risk positions, follow less extreme investment styles and realize less extreme performance outcomes than single managers do.

\section{Group Shift Theory}

Group shift theory suggests that the team opinion deviates from the arithmetic mean of the team members' individual opinions towards the opinion of the most extreme team member. Consequently, teams take on average more extreme decisions as compared to individuals. This implies that teams should hold portfolios with extremely high risk or portfolios with extremely low risk. Consequently, we expect the risk of team managed funds to be more extreme than that of individual managed funds:

H4: Teams choose more extreme risk positions than single managers do.

A similar reasoning applies for the investment styles. Group shift theory predicts that teams will be more extreme than single mangers with respect to their investment styles:

H5: Teams follow more extreme investment styles than single managers do.

More extreme investment strategies in terms of risk and investment style should lead to more extreme performance outcomes. Therefore, group shift theory suggests:

H6: Teams achieve more extreme performance outcomes than single managers do. 
Thus, the two theories lead to contracting hypotheses with respect to the extremity of risk taking (H1 vs. H4), investment style (H2 vs. H5), and performance outcomes (H3 vs. H6).

\section{Data}

Our primary data source is the CRSP Survivor Bias Free Mutual Fund Database. ${ }^{4}$ This database covers U.S. open-end mutual funds and provides information about fund returns, fund management structures, total net assets, investment objectives, and other fund characteristics. We focus on actively managed and broadly diversified domestic equity funds belonging to the market segments 'Long Term Growth', 'Growth \& Income’, and 'Aggressive Growth' (defined according to ICDI objectives). Following the approach in Daniel et al. (1997), we aggregate multiple classes of the same fund to avoid multiple counting since they are backed by the same portfolio and run by the same portfolio manager(s).

CRSP reports management structures of funds in several ways. CRSP provides the name of the fund manager for single managed funds. We classify funds as team managed when CRSP reports "team" or "management team” as management structure. For a third group of funds, CRSP provides the names of two or more fund managers or reports a manager name with the addendum "et al.” or "and team”. We exclude these funds from our sample since it is not clear how this management structure differs from the ones above. ${ }^{5}$ For a fourth group of funds, CRSP reports the name of a management company. These funds are also excluded from our sample since the management structure is unclear. ${ }^{6}$

Our final sample spans the period from January 1994 to December 2003 and includes 9,968 yearly observations. 7,576 observations belong to single managed funds and 2,392 to team managed funds. The funds belong to 629 different fund management companies. Figure 1 plots the percentage of team and single managed funds over time. It covers the years of the

$4 \quad$ Source: CRSP ${ }^{\mathrm{SM}}$, Center for Research in Security Prices. Graduate School of Business, The University of Chicago. Used with permission. All rights reserved. For a more detailed description of the CRSP database, see Carhart (1997) and Elton/Gruber/Blake (2001).

5 For differences between funds that are labelled 'team managed' and funds that give multiple manager names, see Massa/Reuter/Zitzewitz (2007).

$6 \quad$ We use the CRSP database for management information as this database is less used by the media and investors than e.g. Morningstar as a source of information about funds. This gives CRSP the useful characteristic of being a source that firms do not have a direct incentive to influence (see Massa/Reuter/Zitzewitz, 2007). In addition, we verified the management status of a subsample of funds by checking alternative sources (e.g. fund websites, regulatory filings). We find no evidence for serious misspecification. 
rapid growth in team-managed funds. In 1994, only about 3\% of the funds are team managed (representing about 5\% of assets under management). In the following years, this percentage grows rapidly, reaching nearly $36 \%$ in 2003 (representing about $40 \%$ of assets under management).

- Insert FIGURE 1 about here -

Table 1 provides summary statistics of our sample

- Insert TABLE 1 about here -

On average, the funds in our sample are 10.79 years old and manage over 880 million USD. The mean turnover rate is $96.48 \%$ and the mean expense ratio is $1.33 \%$ p.a. To get an idea of potential differences in the characteristics of team versus single managed funds, we also report the summary statistics of the two sub-samples separately. The respective differences are reported in the last column. Team-managed funds are significantly younger (9.38 versus 11.21 years), have higher total net assets (962.22 versus 857.49 million USD), a slightly lower turnover ratio (95.98 \% versus $96.63 \%$ ), and lower expense ratios (1.21\% versus $1.36 \%$ p.a.) as compared to single-managed funds.

The comparison between the two sub-samples shows that team and single manager funds differ significantly with respect to their characteristics. Therefore, we have to control for these differences in our following empirical analysis.

\section{Extremity of Teams and Single Managers}

\subsection{Risk Extremity}

We measure the risk a fund manager takes in three alternative forms: total risk, systematic risk, and unsystematic risk. Total risk is measured as the standard deviation of fund i’s return 
in year $t$. The systematic risk is measured as fund $i$ 's beta in year $t$ from a market model. ${ }^{7}$ The unsystematic risk is measured by the standard deviation of fund i's residual fund return from the market model. The latter two measures are computed based on a regression of fund i's excess return on the market excess return for each year in our sample:

$$
r_{i, m, t}-r_{f, m, t}=a_{i, t}+\beta_{i, t}\left(r_{M, m, t}-r_{f, m, t}\right)+\varepsilon_{i, m, t}
$$

Here, $r_{i, m, t}$ denotes the return of fund $i$ in month $m$ of year $t$ and $r_{i, m, t}-r_{f, m, t}$ denotes the excess return of the market portfolio over the risk-free rate for the same period.

First, to get an idea about the risk distribution, we compute the share of single managed funds in different risk percentiles. The results are provided in Figure 2.

\section{- Insert FIGURE 2 about here -}

For all three risk measures, we observe a U-shaped relationship. The percentage of single managed funds in extreme percentiles (particularly in the top percentiles) is higher than in the middle percentiles. This means that single managers choose considerably higher levels of risk or considerably lower levels of risk as compared to management teams.

To take a closer look at the differences in risk, we compute for each fund $i$ in year $t$ a measure for its risk extremity, $R E_{i, t}$, as the absolute difference between the fund risk, $R_{i, t}$, and its risk benchmark, $\bar{R}_{i, t}$. The risk benchmark is measured as the average risk of all funds belonging to the same market segment as fund $i$ in year $t{ }^{8}$ We normalize this number by dividing it by the average absolute difference in the corresponding market segment and year, $\overline{R E}_{i, t}$, to make our risk extremity measure comparable across segments and time. A fund with average risk extremity has, by construction, a risk extremity measure of 1 . The higher the value of $R E$, the more extreme the risk position of the respective fund is.

\footnotetext{
7 The systematic risk extremity measure is similar to the 'beta-deviation' measure of Chevalier/Ellison (1999a) which is calculated as the absolute difference between a fund's beta and the average beta in the fund's market segment. Results (not reported) are not affected by which average we choose. All results not explicitly reported in the paper are available from the authors upon request.
} 
(2) $\quad R E_{i, t}=\frac{\left|R_{i, t}-\bar{R}_{i, t}\right|}{\overline{R E}_{i, t}}$.

To assess the influence of the management structure on the extremity of fund risk, we relate the risk extremity measure, $R E_{i, t}$, to the fund's management structure and other potentially relevant fund characteristics, such as fund age, size, turnover, and expense ratio. We run model (3) separately for $R E_{i, t}$ based on total risk, systematic risk, and unsystematic risk.

$$
R E_{i, t}=\beta_{1} D_{i, t}^{\text {Team }}+\beta_{2} \text { Age }_{i, t-1}+\beta_{3} \text { Size }_{i, t-1}+\beta_{4} \text { Turnover }_{i, t-1}+\beta_{5} \text { Expenses }_{i, t-1}+\varepsilon_{i, t} .
$$

The team dummy, $D^{\text {Team }}$, equals to one if the fund is managed by a team and zero otherwise. ${ }^{9}$ Age and Size are computed as the logarithm of fund age and total net assets, respectively. Turnover is given by a fund's turnover ratio, Expenses by the fund's expense ratio. We lag these explanatory variables by one year to mitigate potential endogeneity problems. We run the regression including time- and segment fixed effects. The results are provided in Panel A of Table 2.

- Insert TABLE 2 about here -

Panel A of Table 2 shows that management teams choose less extreme risk positions than single managers. This result holds true for all risk measures. The influence of the team dummy is negative and statistically significant at the $1 \%$ level. These results strongly support the diversification of opinion theory (Hypothesis 1) and reject the corresponding Hypothesis 4 from the group shift theory.

Panel B of Table 2 provides additional evidence on the average level of risk taking of team and single managed funds (for which we have no hypotheses based on diversification of

$9 \quad$ We drop observations from years in which the management structure changes. As a robustness check, we rerun our regressions including these observations. If the management structure changes in year $t$, we do not ascribe the fund's risk to the new management until year $t+1$. Results are qualitatively similar. 
opinion theory and group shift theory). We run regression (3), but take the risk, $R_{i t}$, of the fund as dependent variable. Column 1 shows that management teams take less total risk than single managers, which is consistent with recent experimental findings of Rockenbach, Sadrieh, and Mathauschek (2007). This difference in total risk is exclusively driven by the difference in unsystematic risk as shown in Column 2 and 3.

\subsection{Investment Style Extremity}

We capture the investment style of a fund by the style dimensions "small-cap vs. large-cap", “value vs. growth”, and “momentum vs. contrarian”, respectively. We apply a return-based style classification approach and measure a fund's style based on the sensitivities of its return to the various factor benchmarks as suggested in Carhart (1997). For each fund, we construct the yearly factor weightings by estimating the following regression:

$$
r_{i, m, t}-r_{f, m, t}=a_{i, t}+\beta_{i, t}^{1}\left(r_{M, m, t}-r_{f, m, t}\right)+\beta_{i, t}^{2} S M B_{m, t}+\beta_{i, t}^{3} H M L_{m, t}+\beta_{i, t}^{4} M O M_{m, t}+\varepsilon_{i, m, t}
$$

The dependent variable is the monthly return of fund $i$ in month $m$ of year $t, r_{i, m, t}$, less the risk free rate, $r_{f, m, t}$. The independent variables are the excess return of the market portfolio over the risk-free rate, $r_{M, m, t}-r_{f, m, t}$, and the returns on the three factor mimicking portfolios that cover our three style dimensions: the size factor, $S M B$, calculated as the return difference between small and large capitalization stocks, the value factor, $H M L$, calculated as the return difference between high and low book-to-market stocks, and the momentum factor, MOM, calculated as the return difference between stocks with high and low past returns. ${ }^{10} \mathrm{~A}$ high factor loading indicates that the fund manager follows a small-cap rather than a large-cap strategy $\left(\beta^{2}\right)$, a value rather than a growth strategy $\left(\beta^{3}\right)$, and a momentum rather than a contrarian strategy $\left(\beta^{4}\right)$, respectively.

Figure 3 shows the share of single managed funds in different style percentiles.

- Insert FIGURE 3 about here http://mba.tuck.dartmouth.edu/pages/faculty/ken.french/data_library.html, while the momentum factor was kindly provided by Mark Carhart. 
We again find a U-shaped pattern, indicating that single managers realize more extreme (high or low) levels of factor loadings than management teams. This holds for each style dimension separately as well as on an aggregate level: single managers invest strongly in either very small or very large companies, in either growth or value companies, and follow either a very pronounced momentum or a very pronounced contrarian strategy while management teams are less extreme in their investment style.

In order to measure a fund's style extremity, we construct a set of style extremity measures, $S E$, similar to the ones developed for risk extremity. We construct one measure for each style. We define style extremity in the sense of taking a large bet on the size, value, or momentum factor, i.e. having an extremely high or low loading on the $S M B, H M L$, and $M O M$ factor, respectively. We compute for each fund $i$ and year $t$ a style extremity measures, $S E_{i, t}$, as the absolute differences between its factor weightings, $\beta_{i, t}$, and the corresponding segment averages, $\bar{\beta}_{i, t}$, as style benchmarks. We normalize this number by dividing it by the average absolute style difference in the corresponding market segment and respective year, $\overline{S E}_{i, t}$, to make our style extremity measure comparable across styles, segments, and time.

(5) $S E_{i, t}=\frac{\left|\beta_{i, t}-\bar{\beta}_{i, t}\right|}{\overline{S E}_{i, t}}$

To get an additional overall measure for a fund's style extremity, we average the three factor extremity measures per fund. A higher value of a style extremity measure corresponds to a more extreme factor weighting. A fund with average extremity has, by construction, an extremity measure of 1 , overall and for each of the style dimensions.

To determine potential differences between team and single managed funds, we adapt model (3) and use the style extremity measures as dependent variables. Results are presented in Panel A of Table 3.

- Insert TABLE 3 about here - 
The results of Panel A clearly show that teams follow less extreme investment styles than single managers. The coefficient on the team dummy is significantly negative at the $1 \%$ level. This result holds irrespective of whether we use the overall style extremity measure or one of the factor-individual style extremity measures as dependent variable. These results strongly support the diversification of opinion theory (Hypothesis 2) and again reject the group shift theory (Hypothesis 5).

Panel B of Table 3 provides evidence on the average level of factor loadings for team and single managed funds. We have no hypotheses for the average level based on diversification of opinion theory and group shift theory. We run regression (3), but take the style factor loadings, $\beta_{i t}$, of the fund as dependent variables. Our findings show that management teams and single managers follow, on average, similar styles. We find no statistically significant influence of the team dummy on any of the three factor loadings.

\subsection{Performance Extremity}

We now analyze whether the behavioural differences documented above are also reflected in the differences in performance. Given our previous results, we expect teams to achieve less extreme performance outcomes than single managers.

To test our hypotheses, we use three widely applied performance measures: (i) The peer group adjusted net return of a fund is computed as the difference between the return of a fund and the average return of all funds in the same market segment. (ii) Jensen (1968) alpha is the abnormal return of a fund after controlling for its systematic risk. We calculate a Jensen alpha for each fund and year as the intercept from model (1). (iii) The four factor alpha of Carhart (1997) controls not only for the systematic risk but also for the investment style of a fund. It is calculated as the intercept from model (4).

To get a first idea about the performance distribution, we compute the share of single managed funds in different performance percentiles. The results are provided in Figure 4.

\section{- Insert FIGURE 4 about here -}

For all three performance measures, we observe a U-shaped relationship. This suggests that funds with a single manager have a higher probability of ending up in one of the extreme (top or bottom) performance percentiles while teams are more likely found in the middle 
performance percentiles. The pattern is most pronounced if we look at the results for peer group adjusted returns and least pronounced for the four-factor alpha. This is consistent with the idea that the more extreme risk-taking strategies and investment styles of single managers lead to more extreme performance outcomes. Since Jensen (1968) alphas and Carhart (1997) four factor alphas correct for differences in risk taking and investment styles, the difference in performance is less pronounced based on these measures.

To further examine whether this pattern is statistically significant, we develop measures of performance extremity, $P E_{i, t}$, similar to the extremity measures developed above. We define performance extremity in the sense of realizing an extreme (good or bad) performance outcome. For each fund $i$ in each year $t$, performance extremity measures, $P E_{i, t}$, are computed as the absolute difference between a fund's performance, $P_{i, t}$, and the average performance of all funds in the same year and segment, $\bar{P}_{i, t}$. We normalize these numbers by dividing them by the average absolute difference in the corresponding market segment and respective year, $\overline{P E}_{i, t}$, to make our performance extremity measures comparable across performance measures, segments, and time:

(6) $\quad P E_{i, t}=\frac{\left|P_{i, t}-\bar{P}_{i, t}\right|}{P E_{i, t}}$.

A higher value of a performance extremity measure corresponds to a more extreme performance outcome. Similar as above, a fund with average performance extremity has an extremity measure of 1 by construction.

We compute performance extremity with respect to our three performance measures (peergroup adjusted returns, Jensen (1968) alphas, and Carhart (1997) four factor alphas). ${ }^{11}$ To assess the influence of fund management structure on the extremity of fund performance, we relate our three performance extremity measures to the same independent variables as in model (3). Results are presented in Panel A of Table 4.

- Insert TABLE 4 about here and year, as this measure is already defined as the difference between the return of the fund and the average return of all funds in the same segment and year. 
The results clearly indicate that teams are less likely to achieve extreme performance outcomes. The impact of the team dummy is negative and statistically significant at the $1 \%$ level irrespective of which performance measure performance extremity is based upon. The estimated coefficient for performance extremity based on peer-group adjusted returns is $-0.1081 .^{12}$ Consistent with our graphical results, the impact of the team dummy is markedly lower if performance extremity is based on Jensen (1968) alphas and even lower than that if it is based on Carhart (1997) four factor alphas. Again, this can be explained by the fact that more extreme performance outcomes are driven by more extreme risk taking strategies (Section 4.1) and more extreme investment styles (Section 4.2). ${ }^{13}$ Overall, our results again support the diversification of opinion theory (Hypothesis 3) and reject the group shift theory (Hypothesis 6).

While the two theories deliver no hypothesis on the question whether average performance of team and single managed funds differs, we now want to shortly explore this question in order to analyze whether our results are consistent with those of earlier studies. To examine the impact of a fund's management structure on its performance level, we regress each of our three performance measures on a team dummy and the same other independent variables as in model (3). In addition, we control for the fund's performance of the last year to take care of potential performance persistence (see, e.g., Bollen/Busse, 2005). Results are presented in Panel B of Table 4.

We find only small performance differences. While the estimate for the influence of the team dummy is negative, it is only marginally significant for the two alpha measures and insignificant for peer-group adjusted returns. The effect is economically small. This result confirms the results from prior studies on performance differences between teams and single managed funds (see, e.g., Chen et al. 2004).

As an alternative way to easily interpret the economic significance of the impact of the management structure on performance extremity, we also relate the probability of a fund achieving a performance among the top- or bottom- $5 \%$ of the performance distribution using a Logit model. We find that team managed funds are about $40 \%$ less likely to end up in the top or bottom $5 \%$ percentile if performance is measured by peer group adjusted returns. This number decreases to $35 \%$ and $32 \%$ if we use Jensen's alphas and four factor alphas, respectively.

The still significant negative impact of team management on performance extremity based on Carhart (1997) four factor alphas indicates that not all of the difference in performance extremity is driven by the risk and investment style factors we control for. However, the Carhart (1997) four factor alpha does not take into account differences in unsystematic risk. Thus, we also add a fund's unsystematic risk as additional control variable. Results (not reported) show that differences in unsystematic risk do indeed explain part of the difference in performance extremity. However, the estimate for the impact of the team dummy is still significant. 


\section{$5 \quad$ Causality Issues}

Our analysis so far might be plagued by an endogeneity problem. It is possible that the fund management company decides (for some exogenous reason) that a fund has to follow a moderate investment style and hires a team to run that fund. To address this problem, we follow an instrumental variable approach using two stage least squares regressions (2SLS). We choose the fund family policy with respect to team management, Family Policy, as our instrumental variable. It is calculated as percentage of team-managed funds in the respective fund family. As management structures are pretty uniform within fund families, ${ }^{14}$ the dominant management strategy of a family is highly correlated with the management structure of the respective funds, i.e. the instrument is highly correlated with the probability that a fund is managed by a team or a single manager. In addition, we do not expect the management structure policy of the fund family to have a strong impact on the behaviour of the fund managers of individual funds in terms of risk-taking or investment styles except through its management structure.

In the first stage of the 2SLS procedure we relate the team dummy variable, $D^{T}$, to our instrument variable, Family Policy, as well as all other exogenous variables (Age, Size, Turnover, Expenses) used in the regression equation (3). Results are reported in Table 5.

\section{- Insert TABLE 5 about here -}

Although not the focus of this paper, the results of Table 5 provide new insights on the determinants of a fund's management structure: Our instrumental variable is strongly correlated with fund management structure. ${ }^{15}$ The coefficient on the Family Policy Variable is positive and highly significant (1\% level) indicating that funds have a relatively higher probability of being team managed when team management is the dominant management approach in that respective family. ${ }^{16}$ Besides family policy, other fund characteristics have a

In our sample about $80 \%$ of all fund families have more than $90 \%$ of their funds being managed by either only single managers or only teams. problems associated with “weak instruments” (see Murray, 2006).

16 Strictly speaking, we cannot interpret our results in terms of probabilities, because our dependent variable is a non-transformed binary variable and we use a linear regression model. However, results are
} 
significant influence on fund management choice. The younger and the larger a fund, the higher is its probability of being team managed. The age effect reflects the fact that team management became very popular in the late nineties and at the same time a lot of new funds were established. The size effect suggests that teams are particularly employed for more extensive tasks, given that the total amount of money to be managed is a reasonable proxy for how extensive the task of running the fund is. For more extensive tasks, the potential benefit from specialization of several team members becomes more important. Turnover and expenses are not significantly related to management structure.

We now re-do our examinations on risk taking, investment styles and performance outcomes using the "expected management structure" from the first stage as explanatory variable instead of the team dummy used in Section 4. The main results from the second stage risk, style and performance regressions are presented in Panels A to C of Table 6, respectively.

\section{- $\quad$ Insert TABLE 6 about here -}

The results presented in Table 6 all confirm the conclusions drawn in Section 4: (i) Teams follow less extreme risk strategies with respect to total risk, systematic risk, as well as unsystematic risk. (ii) Teams follow less extreme investment styles. This result holds for the aggregate style extremity measure as well as for the factor individual style extremity measures. (iii) Teams achieve less extreme performance outcomes than single managers. This result is strongest in peer-group adjusted returns and least pronounced, but still significant, in Carhart (1997) four-factor alphas. ${ }^{17}$ Overall, the results from the 2SLS analysis also support the diversification of opinion theory (Hypothesis 1, 2, and 3) and reject the group shift theory (Hypothesis 4, 5, and 6).

\section{Conclusion}

This paper provides the first empirical test of the diversification of opinion theory and the group shift theory using real business data. All our results clearly reject the group shift theory and support the diversification of opinion theory: extreme opinions of single team managers

similar when estimating the relation between team management and potential determinants with a logit model.

17 Results (not reported) are also stable if we include unsystematic risk as additional control variable in the first and second stage of the 2SLS. 
average out and, consequently, teams take less extreme decisions than individuals do. We find that teams follow less extreme risk strategies and less extreme investment styles than single managed funds. These differences are also reflected in differences in performance outcomes. While there are only small differences in average performance, single managers are much more likely to achieve extreme (good or bad) performance outcomes.

Our findings contrast to findings derived from experimental settings, which typically support the group shift theory. Possible explanations for this difference are the differences in the complexity of the task and in the level of incentives. Therefore, we conclude from our study that one should be cautious when transferring these experimental findings to real world business settings. 


\section{References}

Adams, R. B., and D. Ferreira, 2007, Moderation in Groups: Evidence from Betting on Ice Break-ups in Alaska, Working Paper.

Bär, M., Kempf, A., and S. Ruenzi, 2005, Team Management and Mutual Funds, Working Paper.

Bollen, N. P. B., and J. Busse, 2001, On the Timing Ability of Mutual Fund Managers, Journal of Finance, 56, 1075 - 1094.

Bollen, N. P. B., and J. Busse, 2005, Short-Term Persistence in Mutual Fund Performance, Review of Financial Studies, 18, 569 - 597.

Carhart, M., 1997, On Persistence in Mutual Fund Performance, Journal of Finance, 52, $57-82$.

Chan, L., Chen, H., and J. Lakonishok, 2002, On Mutual Fund Investment Styles, Review of Financial Studies, 15, 1407 - 1437.

Chen, J., Hong, H., Huang M., and J. D. Kubik, 2004, Does Fund Size Erode Mutual Fund Performance? The Role of Liquidity and Organization, American Economic Review, 94, $1276-1302$.

Chevalier, J., and G. Ellison, 1999a, Career Concerns of Mutual Fund Managers, Quarterly Journal of Economics, 114, 389 - 432.

Chevalier, J., and G. Ellison, 1999b, Are Some Mutual Fund Managers Better Than Others? Cross-Sectional Patterns in Behavior and Performance, Journal of Finance, 54, 875 - 899.

Cohen, S.G., and D. E. Bailey, 1997, What Makes Teams Work: Group Effectiveness Research from the Shop Floor to the Executive Suite, Journal of Management, 23, 239 290.

Cooper, D. J, and J. H. Kagel, 2004, Are Two Heads Better than One? Team versus Individual Play in Signalling Games, American Economic Review, 95, 477 - 509.

Daniel, N. D., M. Grinblatt, S. Titman and R. Wermers, 1997, Measuring Mutual Fund Performance with Characteristics-Based Benchmarks, Journal of Finance, 52, 1035 1058.

Davis, James H., and V. B. Hinsz, 1982, Current Research Problems in Group Performance and Group Dynamics, in: Herman Brandstatter, James H. Davis, and Gisela StockerKreichgauer (eds.): Group Decision-Making, London, Academic Press, 1 - 22. 
Elton, E., Gruber, M., and C. Blake, 2001, A First Look at the Accuracy of the CRSP Mutual Fund Database and a Comparison of the CRSP and Morningstar Mutual Fund Databases, Journal of Finance, 56, 2415 - 2430.

Jensen, M., 1968, The Performance of Mutual Funds in the Period 1945 - 1964, Journal of Finance, 23, 389 - 416.

Kempf, A., and S. Ruenzi, 2007, Tournaments in Mutual Fund Families, forthcoming: Review of Financial Studies.

Kerr N. L., 1992, Group Decision Making at a Multialternative Task: Extremity, Interfaction Distance, Pluralities, and Issue Importance, Organizational Behavior and Human Decision Processes, 52, 64 - 95.

Khorana A., and H. Servaes, 1999, The Determinants of Mutual Fund Starts, Review of Financial Studies, 12, 1043 - 1074.

Lamm, H., and D.G. Myers, 1978, Group-Induced Polarization of Attitudes an Behavior, in: Advances in Experimental Social Psychology, 2, 147 - 195.

Massa, M, J. Reuter, and E. Zitzewitz, 2007, Why Should Firms Share Credit With Employees? Evidence from Anonymously Managed Mutual Funds, Working Paper.

Moscovici, S., and M. Zavalloni, 1969, The Group as a Polarizer of Attitudes, Journal of Personality and Social Psychology, 12, 125 - 135.

Mulvey, P., and H. Klein, 1998, The Impact of Perceived Loafing and Collective Efficacy on Group Goal Processes and Group Performance, Organizational Behavior and Human Decision Processes, 7, 62 - 87.

Murray, M. P., 2006, Avoiding Invalid Instruments and Coping with Weak Instruments, Journal of Economic Perspectives, 20, 111-132.

Myers, D.G., and H. Lamm, 1976, The Group Polarization Phenomenon, Psychological Bulletin, 83, 602 - 627.

Niessen, A., and S. Ruenzi, 2006, Sex Matters: Gender and Mutual Funds, Working Paper.

Prather, L., and K. L. Middleton, 2002, Are N + 1 heads better than one?, The Case of Mutual Fund Managers, Journal of Economic Behavior \& Organization, 47, 103 - 120.

Prather, L., and K. L. Middleton, 2006, Timing and Selectivity of Mutual Fund Managers: An Empirical Test of the Behavioral Decision-Making Theory, Journal of Empirical Finance, 13, $249-273$.

Qiu, J., 2003, Termination Risk, Multiple Managers and Mutual Fund Tournaments, European Finance Review, 7, 161 - 190. 
Rockenbach, B., A. Sadrieh, and B. Mathauschek, 2007, Teams Take the Better Risks, Journal of Economic Behavior and Organization, 63, 412 - 422.

Sah, R. K, and J. Stiglitz, 1986, The Architecture of Economic Systems: Hierarchies and Polyarchies, American Economic Review, 76, 716 - 727.

Sah, R. K, and J. Stiglitz, 1988, Committees, Hierarchies and Polyarchies, The Economic Journal, 98, $451-470$.

Sharpe, W. F., 1981, Decentralized Investment Management, Journal of Finance, 36, 217 234.

Stoner, J. A. F., 1961, A Comparison of Individual and Group Decisions Involving Risk, Master's Thesis. 


\section{Figure 1}

Fund Management Structures over Time

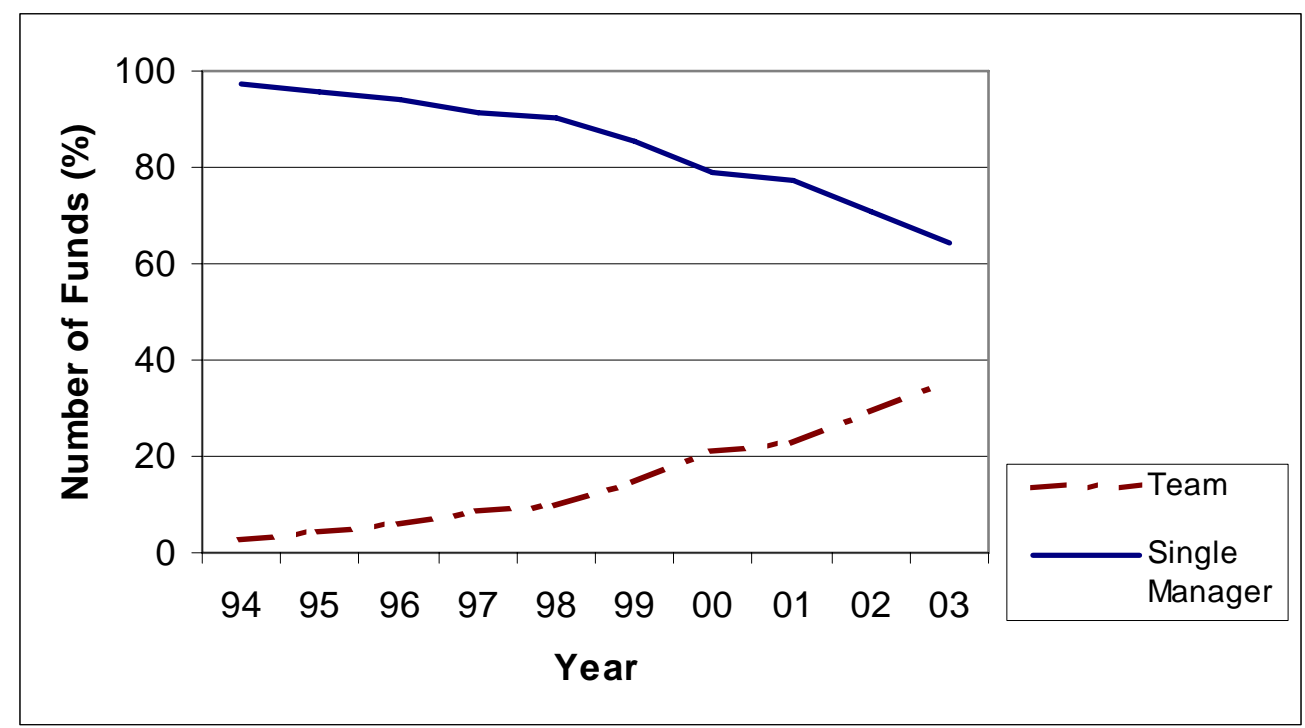

Figure 1 shows the percentage of single managed and team managed funds over time. 
Figure 2

\section{Extremity of Fund Risk}

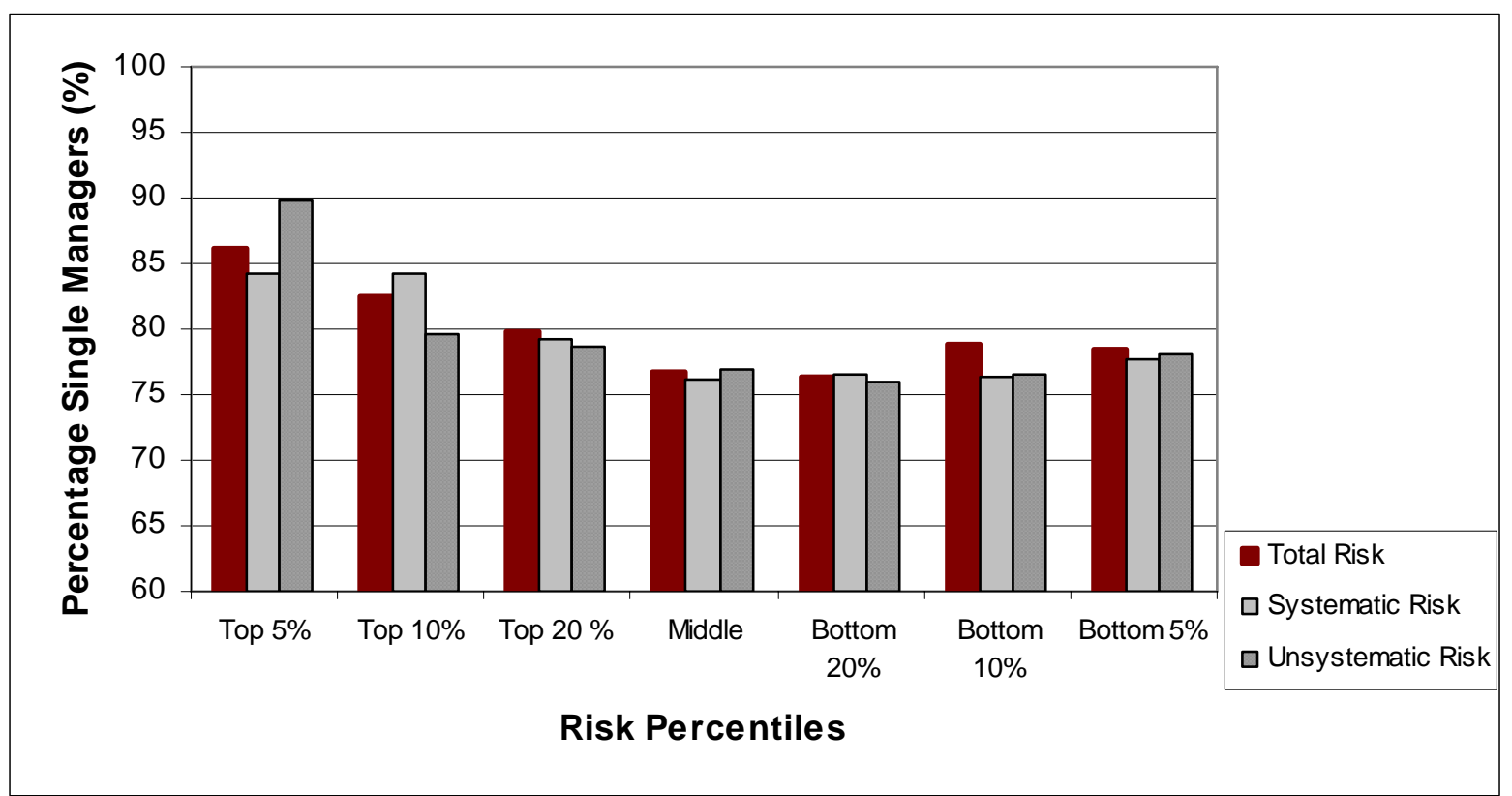

Figure 2 shows the percentage of single managed funds in different risk quintiles. Fund risk is measured by fund total risk, systematic risk, and unsystematic risk. 
Figure 3

Extremity of Fund Style

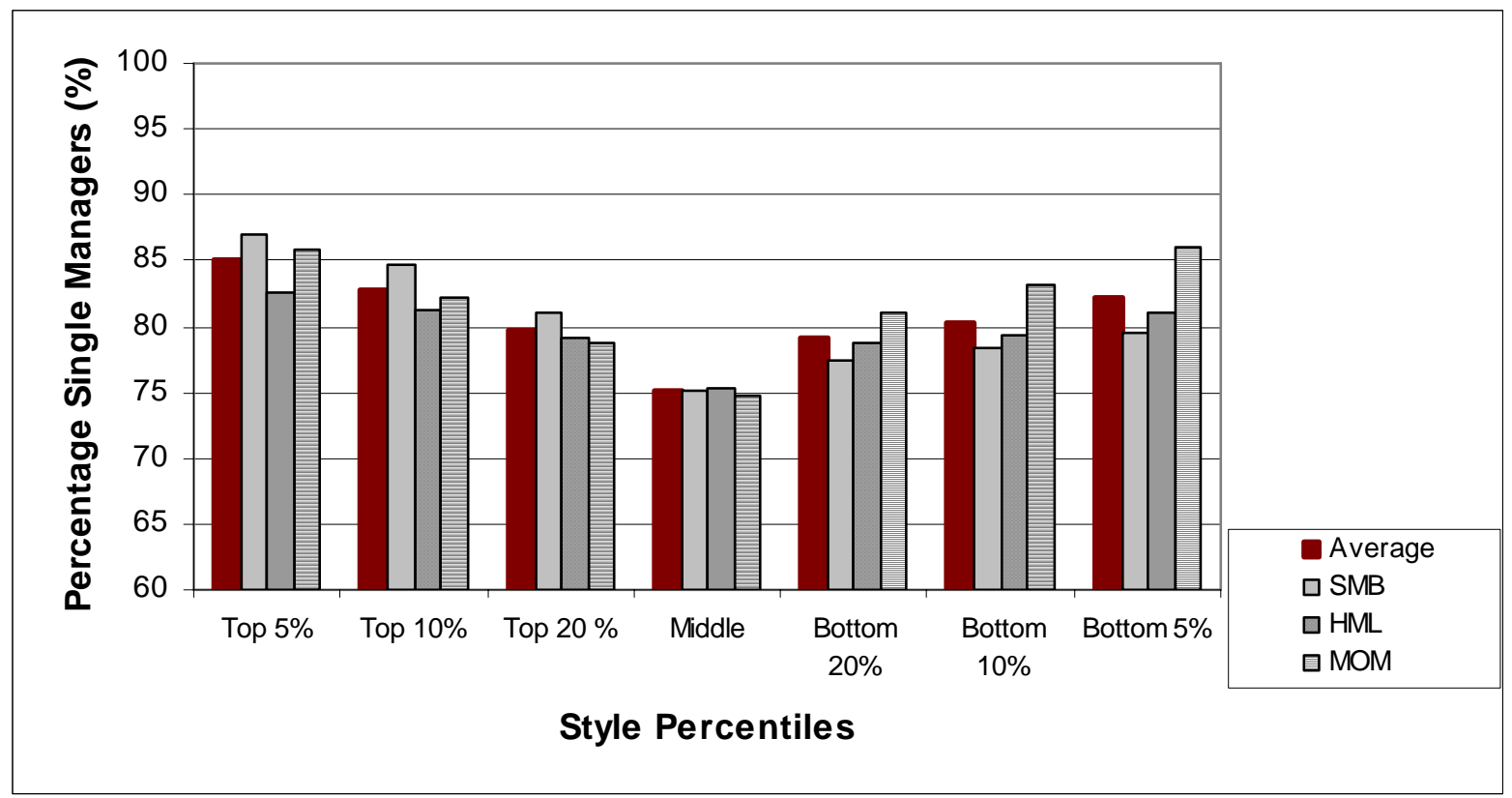

Figure 3 shows the percentage of single managed funds in different style quintiles. Style is measured by the factor loadings on the style factors as determined by model (4). Results are provided for each single style dimension and on an aggregated level (which is constructed as the average of the three factor loadings). 


\section{Figure 4}

\section{Extremity of Fund Performance}

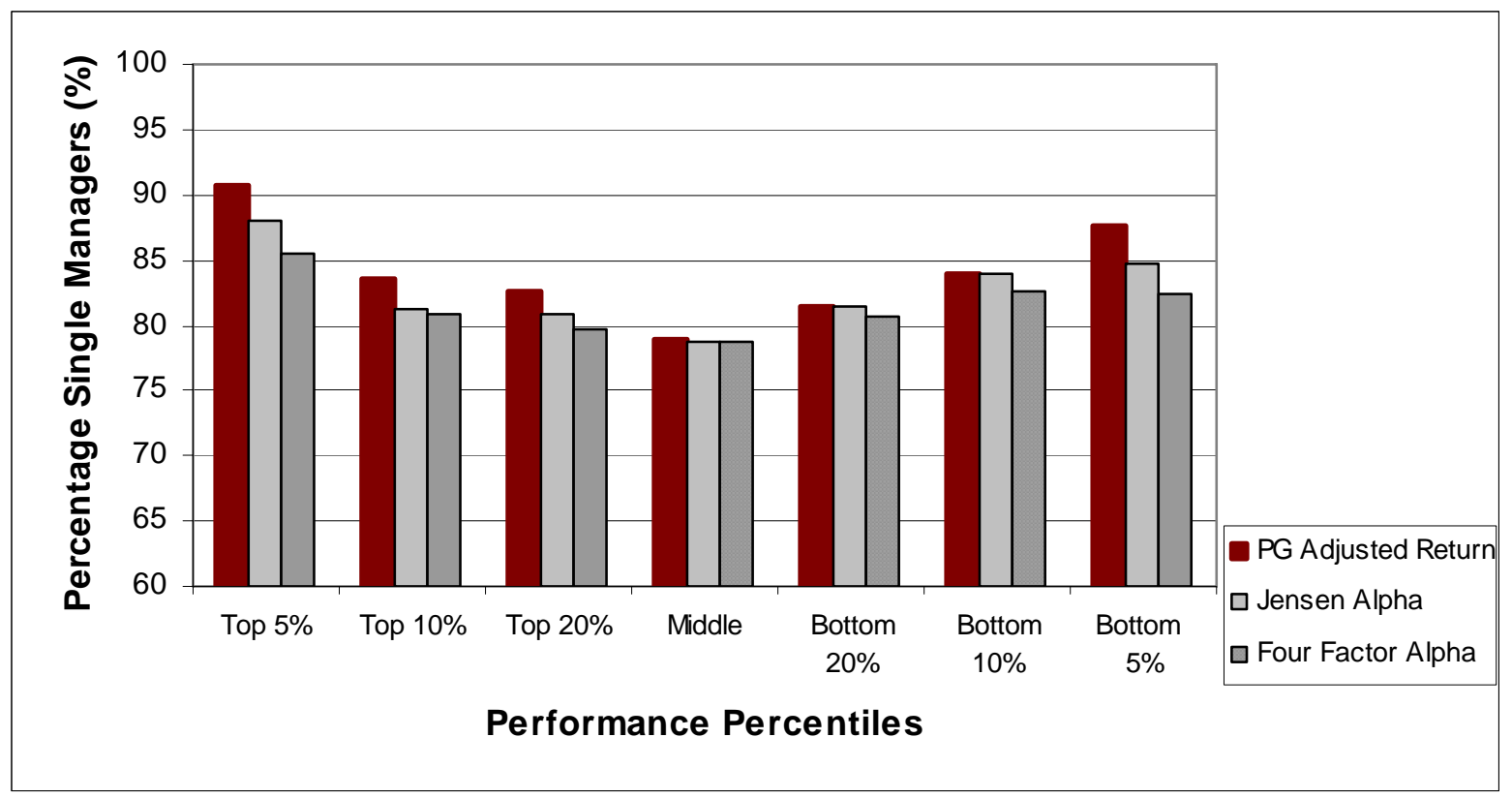

Figure 4 shows the percentage of single managed funds in different performance quintiles. The performance is measured by the peer group adjusted returns, Jensen (1968) alpha from model (1) and the Carhart (1997) four factor alpha from model (4) 


\section{Table 1}

Summary Statistics

\begin{tabular}{l|cccc}
\hline \hline & $\begin{array}{c}\text { All } \\
\text { (Mean) }\end{array}$ & $\begin{array}{c}\text { Team } \\
\text { (Mean) }\end{array}$ & $\begin{array}{c}\text { Single Manager } \\
\text { (Mean) }\end{array}$ & $\begin{array}{c}\text { Difference } \\
\text { (Mean) }\end{array}$ \\
\hline \hline $\begin{array}{l}\text { Age (in Years) } \\
\text { Total Net Assets } \\
\text { (in Millions) }\end{array}$ & 10.79 & 9.38 & 11.21 & $-1.83^{\star \star \star}$ \\
Turnover Ratio (in \%) & 881.52 & 962.22 & 857.49 & $104.73^{\star \star *}$ \\
Expense Ratio (in \%) & 96.48 & 95.98 & 96.63 & $-0.65^{\star}$ \\
\hline \hline
\end{tabular}

*** $1 \%$ significance, $* * 5 \%$ significance, $* 10 \%$ significance

Table 1 presents summary statistics of the actively managed equity mutual funds included in the paper. Funds are grouped by their management structure (all, team, and single manager). The last column shows the differences in fund characteristics between team- and single-managed funds. The number of observations is 9,968. 
Table 2

Panel A: Extremity of Risk Taking

\begin{tabular}{l|ccc}
\hline \hline & \multicolumn{3}{|c}{ Risk Extremity } \\
& Total Risk & Systematic Risk & Unsystematic Risk \\
\hline \hline Team Dummy & $-0.13010^{\star \star \star}$ & $-0.09532^{\star \star \star}$ & $-0.13988^{\star \star \star}$ \\
Age & $0.05128^{\star \star}$ & $0.05337^{\star \star}$ & $0.05187^{\star \star}$ \\
Size & $-0.03910^{\star \star *}$ & $-0.04764^{\star \star *}$ & $-0.02594^{\star \star \star}$ \\
Turnover & $0.18010^{\star \star *}$ & $0.13891^{\star \star \star}$ & $0.20130^{\star \star \star}$ \\
Expenses & 0.03408 & 0.02362 & 0.03721 \\
\hline \hline $\mathbf{R}^{2}$ & 0.0917 & 0.07028 & 0.0929 \\
\hline \hline
\end{tabular}

Panel B: Average Level of Risk Taking

\begin{tabular}{l|ccc}
\hline \hline & \multicolumn{3}{|c}{ Fund Risk } \\
& Total Risk & Systematic Risk & Unsystematic Risk \\
\hline \hline Team Dummy & $-0.00211^{\star \star \star}$ & -0.00909 & $-0.00237^{\star \star \star}$ \\
Age & -0.00006 & $-0.02054^{\star \star}$ & 0.00001 \\
Size & 0.00010 & $0.02018^{\star \star \star}$ & $-0.00100^{\star \star \star}$ \\
Turnover & $0.00441^{\star \star \star}$ & $0.05617^{\star \star \star}$ & $0.00304^{\star \star \star}$ \\
Expenses & 0.00607 & 0.06963 & 0.00479 \\
\hline \hline $\mathbf{R}^{2}$ & 0.4340 & 0.2269 & 0.4292 \\
\hline \hline
\end{tabular}

*** $1 \%$ significance, $* * 5 \%$ significance, $* 10 \%$ significance

Table 2 shows the results of regression (3) with time and segment fixed effects. In Panel A, the dependent variable is the risk extremity, $R E$, as defined in equation (1). In Panel $\mathrm{B}$, the dependent variable is the level of fund risk, $R$. Results are provided for total risk as well as systematic risk and unsystematic risk derived from the market model (2). 
Table 3

Panel A: Extremity of Investment Style

\begin{tabular}{l|cccc}
\hline \hline & \multicolumn{4}{|c}{ Style Extremity } \\
& Average & SMB & HML & MOM \\
\hline \hline Team Dummy & $-0.13975^{\star \star \star}$ & $-0.15225^{\star \star \star}$ & $-0.06215^{\star \star \star}$ & $-0.20484^{\star \star \star}$ \\
Age & $0.01587^{\star \star}$ & 0.01707 & 0.031120 & $0.03154^{\star \star \star}$ \\
Size & $-0.04299^{\star \star \star}$ & $-0.04070^{\star \star \star}$ & $-0.05086^{\star \star \star}$ & $-0.06339^{\star \star \star}$ \\
Turnover & $0.09761^{\star \star \star}$ & $0.06325^{\star \star \star}$ & $0.07122^{\star \star \star}$ & $0.13346^{\star \star \star}$ \\
Expenses & $0.02198^{\star}$ & 0.02020 & 0.02182 & $0.02394^{\star}$ \\
\hline \hline $\mathbf{R}^{2}$ & 0.0854 & 0.0383 & 0.0347 & 0.0594 \\
\hline \hline
\end{tabular}

Panel B: Average Investment Style

\begin{tabular}{l|ccc}
\hline \hline & & Fund Style & \\
& SMB & HML & MOM \\
\hline \hline Team Dummy & -0.01000 & 0.00671 & 0.01597 \\
Age & -0.01166 & 0.00588 & -0.00111 \\
Size & $-0.00915^{\star \star}$ & $-0.01814^{\star \star \star}$ & $0.00864^{\star \star \star}$ \\
Turnover & $0.03155^{\star \star \star}$ & $0.07452^{\star \star \star}$ & $0.03557^{\star \star \star}$ \\
Expenses & -0.01502 & -0.01517 & -0.01445 \\
\hline \hline $\mathbf{R}^{2}$ & 0.2771 & 0.1661 & 0.1507 \\
\hline \hline
\end{tabular}

*** $1 \%$ significance, ** $5 \%$ significance, * $10 \%$ significance

Table 3 shows the results of a modified version of regression (3) with time and segment fixed effects. In Panel A, the dependent variable is the style extremity, SE, as defined in equation (5). In Panel B, the dependent variable is the loading on the style factor as determined by model (4). Results are provided for each single style factor and an aggregate style extremity measure. 


\section{Table 4}

Panel A: Extremity of Fund Performance

\begin{tabular}{|c|c|c|c|}
\hline & \multicolumn{3}{|c|}{ Fund Performance } \\
\hline & $\begin{array}{c}\text { Peer Group } \\
\text { Adjusted Return }\end{array}$ & Jensen Alpha & Four Factor Alpha \\
\hline Team Dummy & $-0.10812^{\star \star \star}$ & $-0.08845^{\star \star *}$ & $-0.07679^{\star \star *}$ \\
\hline Age & $0.03172^{*}$ & $0.03355^{\star \star}$ & $0.03304^{*}$ \\
\hline Size & $-0.03468 *$ & $-0.03296^{*}$ & $-0.03841^{\star *}$ \\
\hline Turnover & $0.13333^{\star \star \star}$ & $0.12947^{\star *}$ & $0.11873^{\star *}$ \\
\hline Expenses & $0.02821^{*}$ & $0.03127^{*}$ & $0.03081^{*}$ \\
\hline $\mathbf{R}^{2}$ & 0.0738 & 0.0768 & 0.0721 \\
\hline
\end{tabular}

Panel B: Average Fund Performance

\begin{tabular}{l|ccc}
\hline \hline & \multicolumn{3}{|c}{ Fund Performance } \\
& $\begin{array}{c}\text { Peer Group } \\
\text { Adjusted Return }\end{array}$ & Jensen Alpha & Four Factor Alpha \\
\hline \hline Team Dummy & -0.00852 & $-0.00108^{\star}$ & $-0.00067^{*}$ \\
Previous Performance & $0.12016^{\star \star \star}$ & $0.22903^{\star \star \star}$ & $0.10456^{\star \star \star}$ \\
Age & $-0.00419^{\star}$ & 0.00003 & $-0.00026^{*}$ \\
Size & $-0.00649^{\star \star *}$ & $-0.00057^{\star \star *}$ & $-0.00034^{\star \star *}$ \\
Turnover & $0.00536^{\star \star}$ & -0.00021 & -0.00054 \\
Expenses & $-0.27345^{\star \star *}$ & $-0.19407^{\star \star *}$ & $-0.13241^{\star \star *}$ \\
\hline \hline $\mathbf{R}^{2}$ & 0.0905 & 0.2294 & 0.1624 \\
\hline \hline
\end{tabular}

*** $1 \%$ significance, $* * 5 \%$ significance, $* 10 \%$ significance

Table 4 shows the results of a modified version of regression (3) with time and segment fixed effects. In Panel A, the dependent variable is the performance extremity, $P E$, as defined in equation (6). In Panel $\mathrm{B}$, the dependent variable is a fund's performance. Results are provided for peer group adjusted returns, Jensen (1968) alphas from model (1) and Carhart (1997) four factor alphas from model (4), respectively. 


\section{Table 5}

First Stage of 2SLS

\begin{tabular}{l|c}
\hline \hline & Team Management \\
\hline \hline Family Policy & $0.90621^{\star \star \star}$ \\
Age & $-0.00572^{\star \star}$ \\
Size & $0.00371^{\star \star}$ \\
Turnover & -0.00388 \\
Expenses & -0.03151 \\
\hline \hline $\mathbf{R}^{2}$ & 0.6288 \\
\hline \hline
\end{tabular}

*** $1 \%$ significance, $* * 5 \%$ significance, $* 10 \%$ significance

Table 5 shows the results of the first stage regression of a 2 SLS regression with time and segment fixed effects. The dependent variable is the team dummy variable which takes the value one for team managed funds and the value zero otherwise. 


\section{Table 6}

Panel A: Second Stage of 2SLS on Risk Extremity

\begin{tabular}{l|ccc}
\hline \hline & & \multicolumn{3}{c}{ Risk Extremity } \\
& Total & Systematic Risk & Unsystematic Risk \\
\hline \hline Team Dummy & $-0.15214^{\star \star \star}$ & $-0.11772^{\star \star \star}$ & $-0.14100^{\star \star \star}$ \\
Age & $0.04255^{\star \star}$ & $0.03132^{\star \star}$ & $0.04350^{\star}$ \\
Size & $-0.07491^{\star \star *}$ & $-0.06772^{\star \star *}$ & $-0.06182^{\star \star \star}$ \\
Turnover & $0.18339^{\star \star *}$ & $0.13560^{\star \star *}$ & $0.19013^{\star \star \star}$ \\
Expenses & 0.03415 & 0.02429 & 0.03626 \\
\hline \hline $\mathbf{R}^{2}$ & 0.0901 & 0.0685 & 0.0866 \\
\hline \hline
\end{tabular}

Panel B: Second Stage of 2SLS on Style Extremity

\begin{tabular}{l|cccc}
\hline \hline \multirow{2}{*}{ Team Dummy } & \multicolumn{4}{|c}{ Style Extremity } \\
& Average & SMB & HML & MOM \\
\hline \hline Age & $-0.15481^{\star \star \star}$ & $-0.17490^{\star \star \star}$ & $-0.07231^{\star \star}$ & $-0.21722^{\star \star \star}$ \\
Size & 0.01298 & -0.00751 & $0.01889^{\star}$ & $0.02378^{\star}$ \\
Turnover & $-0.04105^{\star \star \star}$ & $-0.03493^{\star \star \star}$ & $-0.03714^{\star \star \star}$ & $-0.05108^{\star \star \star}$ \\
Expenses & $0.08554^{\star \star *}$ & $0.06710^{\star \star \star}$ & $0.05414^{\star \star *}$ & $0.12438^{\star \star *}$ \\
\hline \hline $\mathbf{R}^{2}$ & 0.02118 & 0.01680 & 0.02210 & 0.02468 \\
\hline \hline
\end{tabular}

Panel C: Second Stage of 2SLS on Performance Extremity

\begin{tabular}{l|ccc}
\hline \hline & \multicolumn{3}{|c}{ Performance Extremity } \\
& $\begin{array}{c}\text { Peer Group } \\
\text { Adjusted Return }\end{array}$ & Jensen Alpha & Four Factor Alpha \\
\hline \hline Team Dummy & $-0.11686^{\star \star *}$ & $-0.06877^{\star \star *}$ & $-0.06016^{\star *}$ \\
Age & 0.02177 & $0.03445^{\star}$ & $0.03557^{*}$ \\
Size & $-0.02664^{\star}$ & $-0.02880^{\star *}$ & $-0.03987^{\star *}$ \\
Turnover & $0.13573^{\star * *}$ & $0.13157^{\star *}$ & $0.10624^{\star *}$ \\
Expenses & 0.02796 & $0.03203^{*}$ & $0.03091^{\star}$ \\
\hline \hline $\mathbf{R}^{2}$ & 0.0691 & 0.0785 & 0.0735 \\
\hline \hline
\end{tabular}

*** $1 \%$ significance, ** $5 \%$ significance, * $10 \%$ significance

Table 6 shows the results of the second stage regression of a 2 SLS regression with time and segment fixed effects. The dependent variable is the risk extremity, $R E$, as defined in equation (1) (Panel A), the style extremity, SE, as defined in equitation (5) (Panel B), and performance extremity, PE, as defined in equation (6) (Panel C), respectively. 